\title{
LA-UR-17-27014
}

Approved for public release; distribution is unlimited.

Title: Integrated Work Management: Preparer, Course 31883

Author(s): $\quad$ Simpson, Lewis Edward

Intended for: Training

Issued: 
Disclaimer:

Los Alamos National Laboratory, an affirmative action/equal opportunity employer, is operated by the Los Alamos National Security, LLC for the National Nuclear Security Administration of the U.S. Department of Energy under contract DE-AC52-06NA25396. By approving this article, the publisher recognizes that the U.S. Government retains nonexclusive, royalty-free license to publish or reproduce the published form of this contribution, or to allow others to do so, for U.S. Government purposes. Los Alamos National Laboratory requests that the publisher identify this article as work performed under the auspices of the U.S. Department of Energy. Los Alamos National Laboratory strongly supports academic freedom and a researcher's right to publish; as an institution, however, the Laboratory does not endorse the viewpoint of a publication or guarantee its technical correctness. 


\section{Integrated Work Management: Preparer COURSE 31883}

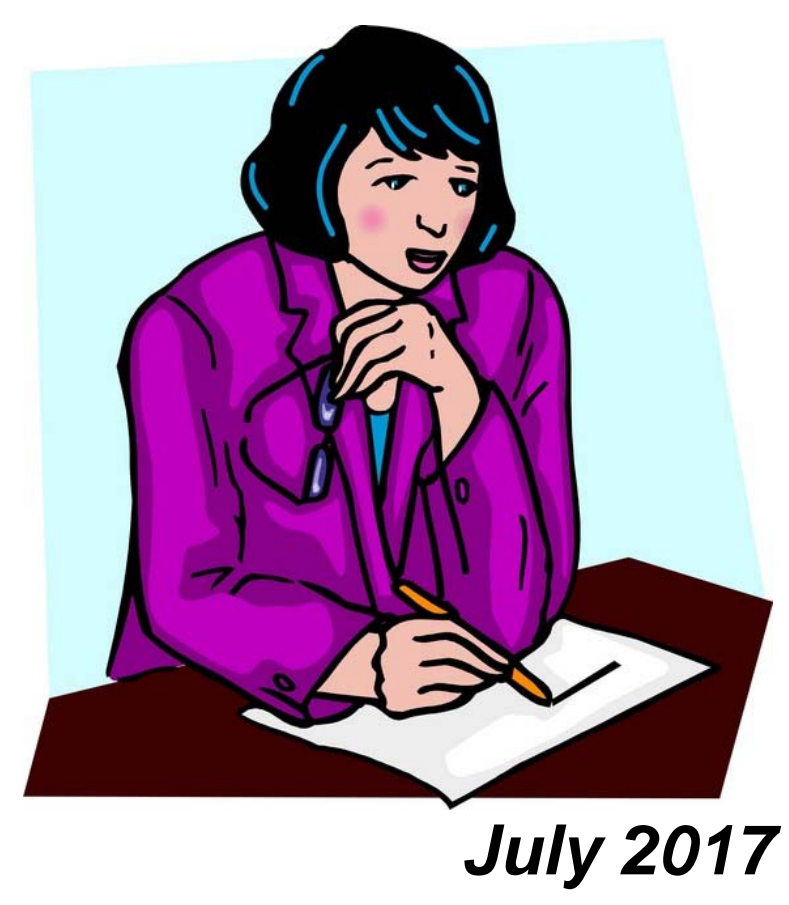


This training course was prepared by Los Alamos National Security, LLC (LANS) under Contract DE-AC52-06NA25396 with the U.S. Department of Energy, National Nuclear Security Administration (DOE/NNSA). All rights in the material are reserved by DOE and LANS pursuant to the contract. This training course is presented with the understanding that the information and materials provided were developed based on specific circumstances present at the Los Alamos National Laboratory at the time of publication. Those circumstances may or may not be similar to conditions present at other locations represented by participants in this course. The course materials and information will need to be adapted accordingly. NEITHER THE DOE/NNSA, NOR LANS, NOR ANY OF THEIR EMPLOYEES, MAKES ANY WARRANTY, EXPRESS OR IMPLIED, OR ASSUMES ANY LEGAL LIABILITY OR RESPONSIBILITY FOR THE ACCURACY, COMPLETENESS, OR USEFULNESS OF ANY INFORMATION, APPARATUS, PRODUCT, OR PROCESS DISCLOSED AND WILL NOT BE LIABLE FOR DIRECT OR INDIRECT DAMAGES RESULTING FROM USE OF THIS MATERIAL.

\section{Central Training-Institutional Training Services Group Leader \\ Cindy Dutro}

Course Manager

Lewis E. Simpson

Technical Advisor

Cheryl Lucas

Editor/Compositor

Lisa Rothrock

COURSE 31883

July 2017

LA-UR-17-

Controlled Document Number: IWMPrepr_31883_SS,R2.0 


\section{Contents}

Introduction

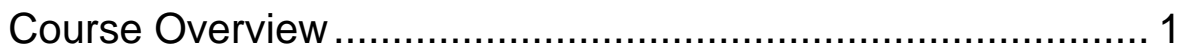

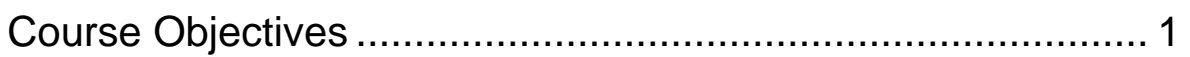

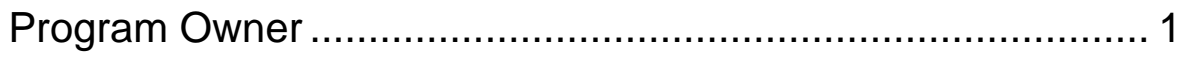

Target Audience and Training Requirements ......................... 1

IWM Requirements Documents.............................................. 2

About This Self-Study Course ........................................ 2

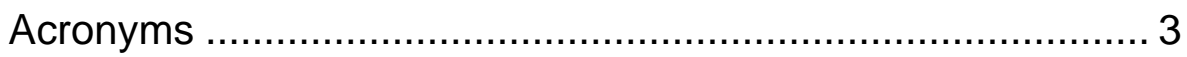

Module 1: IWM Process Overview ................................................ 4

The IWM Process..................................................................... 4

Tailored Approaches for Implementing IWM ……................. 5

Preparer's Step-by-Step Process ....................................... 6

Identify Controls ............................................................ 13

Scoping Walk-Downs ...................................................... 17

Coordination of Activities with Multiple Workers/Locations..... 19

Module 2: Preparing the IWD ................................................... 20

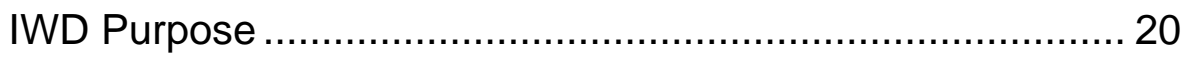

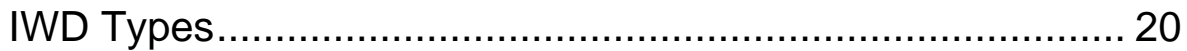

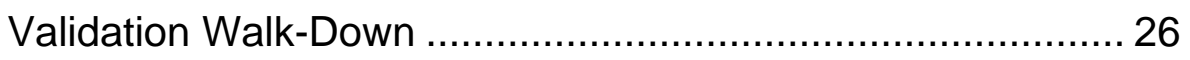

Module 3: Hazard Analysis Methods ....................................... 28

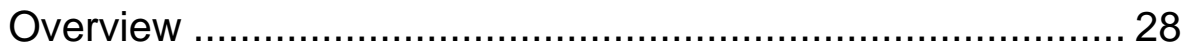

What-If/Checklist Technique ............................................. 29

HAZOP Analysis............................................................ 30

Failure Modes and Effects Analysis (FMEA) ........................ 31

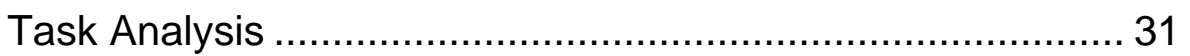

Procedure Analysis................................................... 32

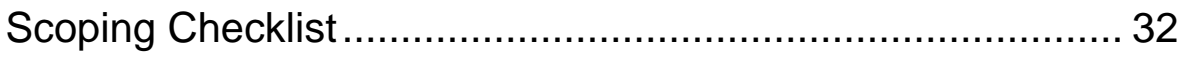

Barrier Analysis .............................................................. 33

Fault-Tree (Human Reliability) Analysis ............................... 34

Human Performance Improvement's (HPI's) Role in Hazard

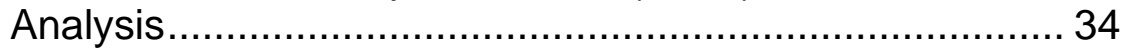

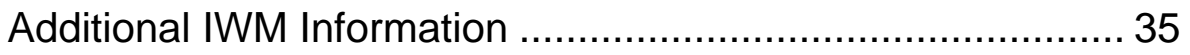




\section{Introduction}

\section{Course Overview}

The preparer (also called the "planner") plays a key role in the integrated work management (IWM) process at Los Alamos National Laboratory (LANL). This course, Integrated Work Management: Preparer (COURSE 31883), describes the IWM roles and responsibilities of the preparer. This course also discusses IWM requirements that must be met by the preparer.

For a general overview of the IWM process, see COURSE 31881, Integrated Work Management: Overview.

\section{Course Objectives}

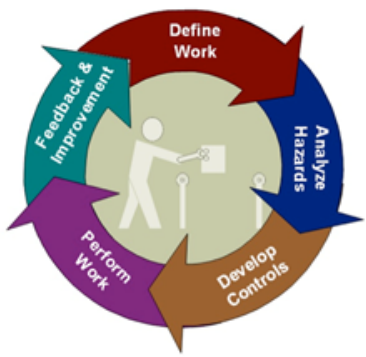

When you have completed this course, you will recognize the preparer's roles and responsibilities in the IWM process. You will also recognize the requirements associated with

- Defining the work

- Identifying and analyzing hazards

- Grading the hazard level

- Developing controls

- Writing the integrated work document (IWD)

\section{Program Owner}

This course was developed under the direction and technical oversight of the Associate Director for Nuclear and High Hazard Operations (ADNHHO), who is the functional program owner for this training.

\section{Target Audience and Training Requirements}

This course is recommended for all preparers of moderate-hazard and high-hazard/complex IWDs. For additional training recommendations, see the Training Table in the IWM Toolbox (link). 


\section{IWM Requirements Documents}

The primary LANL document that establishes and describes IWM requirements is P300 Integrated Work Management. SD312, LANL Management Models.

\section{About This Self-Study Course}

IWM: Preparer (COURSE 31883) consists of an introduction, three modules, and a quiz. To receive credit in UTrain for completing this course, you must score $80 \%$ or better on the 10 -question quiz. Directions for initiating the quiz are appended to the end of this training manual.

This course contains several links to LANL websites. UTrain might not support active links, so please copy and paste these links into the address line in your browser.

Note: In this course, the term "IWD" refers to any integrated work document or equivalent work control document (WCD). The term "preparer" also refers to the term "planner" in some organizations. 


\section{Acronyms}

$\begin{array}{ll}\text { ADESH\&Q } & \begin{array}{l}\text { Associate Director for Environment, Safety, Health, } \\ \text { and Quality } \\ \text { Associate Director for Nuclear and High-Hazard } \\ \text { Operations }\end{array} \\ \text { ADPSM } & \begin{array}{l}\text { Associate Directorate of Plutonium Science and } \\ \text { Manufacturing }\end{array} \\ \text { dC } & \text { Direct Current } \\ \text { ES\&H } & \text { Environment, Safety, and Health } \\ \text { ESH\&Q } & \text { Environment, Safety, Health, and Quality } \\ \text { FMEA } & \text { Failure Modes and Effects Analysis } \\ \text { FOD } & \text { Facility Operations Director } \\ \text { GET } & \text { General Employee Training } \\ \text { HA } & \text { Hazard Analysis } \\ \text { HAZOP } & \text { Hazard and Operability } \\ \text { HPI } & \text { Human Performance Improvement } \\ \text { IWD } & \text { Integrated Work Document } \\ \text { IWM } & \text { Integrated Work Management } \\ \text { JHA } & \text { Job Hazard Analysis } \\ \text { LANL } & \text { Los Alamos National Laboratory } \\ \text { P } & \text { Procedure } \\ \text { PIC } & \text { Person in Charge } \\ \text { PPE } & \text { Personal Protective Equipment } \\ \text { R\&D } & \text { Research and Development } \\ \text { RCRA } & \text { Resource Conservation and Recovery Act } \\ \text { RLM } & \text { Responsible Line Manager } \\ \text { S\&S } & \text { Security and Safeguards } \\ \text { SIWD } & \text { Standing Integrated Work Document } \\ \text { SME } & \text { Subject Matter Expert } \\ \text { SWCD } & \text { Standing Work Control Document } \\ \text { WCD } & \text { Work Control Document }\end{array}$




\section{Module 1: IWM Process Overview}

\section{The IWM Process}

The IWM process can be divided into the following nine steps:

1. Define the work

2. Analyze hazards

3. Develop controls

4. Prepare the IWD

5. Perform a validation walk-down of the IWD

6. Conduct a pre-job briefing and release of work

7. Perform the work safely, securely and in an environmentally responsible manner

8. Conduct periodic readiness checks

9. Conduct a post-job review

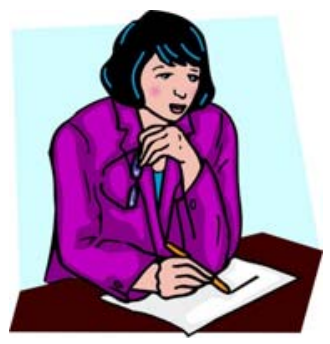

\section{Preparer}

The preparer is assigned by the responsible line manager (RLM) and has the responsibility and authority to establish and document the risk management envelope for a work activity. The preparer is encouraged to identify the roles and responsibilities of the persons performing every step within a WCD.

The Preparer:

- Is accountable to a line manager and has authority to control and manage the planning of a WCD, including the resolution of comments and coordination of approvals. The preparer may be a subcontractor.

- Is technically competent to prepare the WCD or ensures that technically competent personnel are called on to assist in developing the WCD.

- Considers appropriate lessons learned and operating experience applicable to the specific planned activity in preparing WCDs as directed by the RLM. 


\section{Tailored Approaches for Implementing IWM}

P300 Integrated Work Management defines the requirements and expectations for conducting, authorizing, and coordinating all activity-level work at LANL. Because of the diversity of activities, one specific approach cannot be optimal for all situations. P300 therefore allows for tailoring the implementation to meet more specific organizational needs.

Access the IWM websites at http://int.lanl.gov/org/padops/a dnhho/operations-

support/IWM/index.shtml and http://int.lanl.gov/safety/integrat ed work management/index.s
This flexibility has enabled the incorporation of additional process-specific requirements that either supplement or provide alternate, tailored approaches for meeting P300 requirements. For instance, templates for IWD Parts 1, 2, 3, and 4 are provided on the IWM website and in the LANL Forms Center; users may use them or develop their own equivalent WCD, as long as it meets $\mathrm{P} 300$ requirements and incorporates equivalent data, including authorizations identified in the current P300 forms.

When a more specific approach has been developed to address organizational or process needs, the tailored requirements should be followed during the conduct of affected work activities. The following modes of work, organizational implementation, and supplemental requirements are recognized in P300:

- Research and Development (R\&D)

- Facilities and Maintenance

- Operations

- Subcontractors

- Security

P300, Section 2.2, Applicability provides additional details and requirements for each of these implementation approaches. 
In addition to the approaches discussed in P300, a variety of organizational and facility-specific approaches have been developed for implementing the IWM process. For instance, IWM implementation within the Associate Directorate of Plutonium Science and Manufacturing (ADPSM) relies on a system of detailed operating procedures and the document control system Documentum. You will need to check with local Environmental Safety, and Health (ES\&H) staff, line management, and/or facility personnel to ensure that you are meeting local requirements.

\section{Preparer's Step-by-Step Process}

The following sections cover more specific information about the preparer's duties during each step of the IWM process.

\section{Define the Work}

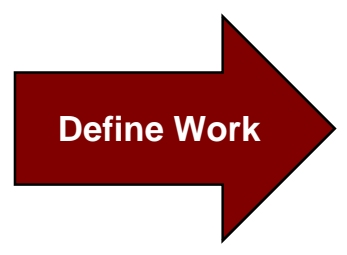

Work components and processes must be defined in sufficient detail to identify and analyze hazards and the circumstances in which they could cause harm. Defining the work generally requires each of the tasks and work steps within an activity to be identified, defined, and planned so that the associated hazards can be mitigated adequately. The work definition should include factors such as the

- Planned envelope in which the activity will be performed

- Facility and/or location where the work will be performed

- Configuration and use of equipment

- Method of work (e.g., scraping, grinding, and sanding)

- Use of classified or sensitive information or components

- Effects on the environment, including chemical and materials use, waste streams, and other potential environmental impacts

- Impacts to all involved workers (e.g., support and co-located) 
One RLM must be identified as responsible and accountable for the safety, security, and environmental compliance of each work activity. The RLM for the activity is responsible for defining the work in sufficient detail to identify and analyze the hazards. The RLM and/or person in charge (PIC) should engage appropriate subject matter experts (SMEs) to assist in work-planning activities, define the scope and method of work, and ensure the appropriate level of detail (subject to further refinement in subsequent steps of defining the work). The RLM and PIC determine jointly whether workplanning activities require a scoping walk-down.

\section{SME Review}

P300 recognizes two types of SMEs: ES\&H and technical. Participation by either ES\&H or technical SMEs or both may be necessary to define the work adequately, identify hazards, and evaluate the adequacy of controls.

- ES\&H SMEs include designated organizational experts representing LANL core safety programs, such as radiological control technicians, industrial hygienists, waste management coordinators, and electrical safety officers. ES\&H SME participation is required during the hazard analysis (HA) associated with high-hazard/complex activities and may be required during the $\mathrm{HA}$ for moderate-hazard activities (see the table from P300, which is reproduced below).

\begin{tabular}{|c|c|c|c|}
\hline \multicolumn{4}{|c|}{ Environment, Safety, and Health (ES\&H) SME Involvement } \\
\hline \multirow[b]{2}{*}{ Hazard Level } & \multicolumn{3}{|c|}{ Activity } \\
\hline & Hazard Category & Define Work & Hazard Analysis \\
\hline High/Complex & SME recommended & SME recommended & SME mandatory \\
\hline Moderate & SME recommended & SME recommended & $\begin{array}{l}\text { SME recommended/ } \\
\text { mandatory* }\end{array}$ \\
\hline Low & SME recommended & SME recommended & $\mathrm{n} / \mathrm{a}$ \\
\hline \multicolumn{4}{|c|}{$\begin{array}{l}\text { *SME participation is mandated by specific requirements when moderate-hazard (and high- } \\
\text { hazard/complex) work involves, but is not limited to, activities such as energized electrical, explosives, } \\
\text { radiological, beryllium, confined space, hot work, and/or environmental. }\end{array}$} \\
\hline \multicolumn{4}{|c|}{$\begin{array}{l}\text { SMEs may reside in Environment, Safety, and Health (ESH) Divisions or may be deployed to the } \\
\text { various FODs. In addition, there are programs where the SME resides within the line organizations } \\
\text { (e.g., electrical, explosive, and laser safety officers). }\end{array}$} \\
\hline
\end{tabular}


The involvement of ES\&H SMEs also may be mandated specifically by other requirements or may be indicated because of expertise relative to the nature of the work. The following lesson learned resulted from a failure to recognize the need for assistance from an ES\&H SME:

On March 20, 2009, a technician came into contact with about 3570 volts direct current (dc). The dc shock resulted in small seconddegree burns on a thumb and one finger, a first-degree burn on another finger, and two small second-degree burns on his stomach. A subsequent investigation determined that, because of a weakness in the hazard analysis for this activity, an appropriate SME was not included in the hazard analysis review; therefore, the electrical hazards and activity controls were not properly evaluated.

For additional details, see the LANL Team Investigation Report for the Electrical Shock Event (LA-UR-09-02399).

- Technical SMEs include technical or programmatic experts who have knowledge relevant to the hazards involved in the work or the work process itself. For high-hazard/complex R\&D work, the participation of technical SMEs on the HA review team is required.

\section{Identify and Analyze Hazards}

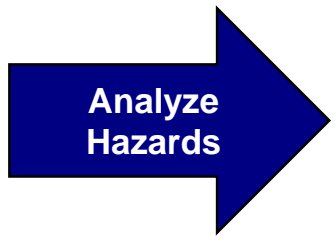

Hazards and accident scenarios that could cause harm must be identified and analyzed using a graded approach to determine what controls are needed to eliminate or reduce the hazards to manage risks to an acceptable level.

- The RLM or designee will, in conjunction with the work planners, determine the hazard grading level with input from the workers, or worker representatives and from the SMEs.

- As part of this determination, RLMs will consult with the appropriate ESH SME, as necessary, to determine the complexity of a work activity and its impact on the determination of hazard level and risk.

- The RLM makes the final decision on the hazard level based typically on input from SMEs unless the RLM is also an SME relative to the work to be performed.

- The impact of the planned work on co-located activities and workers must be considered and addressed. 
IWDs or equivalent WCDs used in the field will include only that which is necessary to perform and document the work properly such that worker safety, safety of the public, and protection of the environment, are ensured. Documents that are not required explicitly to support work will not be required to be at the job site, unless they are absolutely required to be there by a regulatory or permit requirement. Other documentation necessary to ensure thorough identification of hazards, such as

- facility drawings,

- sketches,

- photographs,

- facility safety plans (FSPS),

- schematics of hidden systems, and

- survey results, (radiation survey maps and utility locates);

will be referenced in the IWD/WCD, unless it is necessary to include them in the IWD/WCD to support worker, public, and environmental safety.
The Hazard Grading Table, Attachment B of P300, must be used by the RLM or designee (who in most cases is the PIC) to assign the hazard level of each activity. Attachment B designates three IWM hazard levels: low, moderate, and high/complex; each has specific requirements. (Note: The examples listed in the table are meant to be illustrative and do not represent a complete set of hazards.)

- When answering the hazard grading questions, both activity and work-area hazards must be considered, such as when a lowhazard activity is performed in an area where it is co-located with high-hazard/complex work activity hazards.

- When in doubt about the appropriate grading level, use the next higher level.

- Consult with SMEs who have specific process knowledge or knowledge of the applicable hazards to assist with hazard classification.

\section{Low-Hazard Work}

Low-hazard work involves only everyday hazards that could cause negligible harm and can be controlled by means well known to the workers. For low-hazard work, a complete IWD or WCD is not required unless stipulated by the RLM and FOD, and a formal hazard identification and an analysis are not required.

All low-hazard activities are subject to facility-specific access, facility postings, coordination, and scheduling requirements and must apply work-area controls required by the facility operations director (FOD). Low-hazard work can be controlled by the implementation of other processes; however, the RLM and FOD may require that a complete IWD or equivalent WCD be developed based on their review of hazards and controls.

Note: The IWM Toolbox located on the IWM website contains a Risk Matrix Work Aid (located under Tools > Hazards Analysis), which may be used in evaluating and determining residual risk and hazard levels. 


\section{Moderate-Hazard Work}

Moderate-hazard work involves hazards that inherently could cause moderate harm, such as an injury requiring medical attention or leading to temporary disability and/or a spill or unplanned release to the environment of hazardous materials. Moderate-hazard work as determined by use of the Hazard Grading Table requires an IWD, and a systematic HA must be performed to determine the hazards associated with potential accidents or incidents and how harm might be caused.

- The analysis should be graded based on the complexity of the activity, ranging from a relatively quick "brainstorming" for simple activities to a formal HA method such as the "what-if" checklist or hazard and operability (HAZOP) analysis.

- Workers representative of those involved in the activity are expected to contribute to the analysis.

\section{High-Hazard/Complex Work}

High-hazard/complex work involves

- Hazards that inherently could cause critical or catastrophic harm to people, property, national security, the environment, or the institution, such as

- Severe or fatal injuries, life-shortening disease, and permanent disability;

- Major environmental contamination or permit violation; and/or

- Unfamiliar hazards or a combination of moderate hazards (as defined above) and significant complexity.

For high-hazard/complex work:

- An IWD is required

- a formal "what if," HAZOP, or other effective hazard analysis technique must be used 
- An HA team, including appropriate SME involvement, are expected to perform the HA:

- This analysis is expected to be performed by an HA team with the appropriate depth and breadth of expertise to identify and analyze the hazards thoroughly and to determine how to achieve effective hazard mitigation.

- The HA team must include workers or a representative set of workers, depending on the activity scope.

- In some cases, such as maintenance work activities, individuals technically qualified and knowledgeable of the work activity can participate on the HA team as a representative for the workers who may be assigned to the work.

- The names of the team participants must be documented (such as on Form 2100 or equivalent WCD), unless specifically exempted by the RLM and FOD.

\section{Develop and Implement Controls}

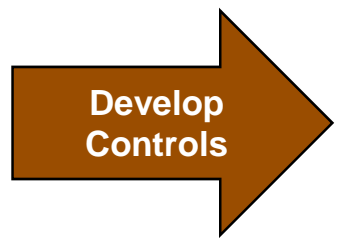

Controls must be defined and implemented, as needed, to reduce the hazards associated with the work to an acceptable level. To mitigate the hazards effectively, the HA team must

- Identify all requirements and controls applicable to the planned work

- Input appropriate controls into the WCDs based on the outcome of the HA

- Use controls selected based on their ability to reduce the probability and/or consequence of adverse events

- Establish controls based on the following hierarchy:

1. Elimination or substitution of the hazards where feasible and appropriate

2. Engineering controls where feasible and appropriate

3. Work practices and administrative controls that limit worker exposures

4. Personnel protective equipment (PPE) 
- Analyze, with a rigor commensurate with the hazard level, potential failures of controls, equipment, utilities, facility systems, procedures, or human factors and establish enhancements and/or alternatives as needed

- Develop permits, plans, or special procedures required for the work, as specified by institutional procedures such that conflicts in hazards and controls and inconsistencies between documents, including the WCD, are resolved.

Examples of types of required permits, plans, or procedures include

- Energized Electrical Work Permits

- Excavation/Fill/Soil Permit Identification

- National Environmental Policy Act

- Air Permits

- Resource Conservation and Recovery Act (RCRA)

- Penetration Permits

- Spark- or Flame-Producing Permits

- Confined Space Entry Permits

- Lockout/Tagout specific written procedures

- Radiological Work Permits

- Fall Protection Plans 


\section{Identify Controls}

\section{Hierarchy of Controls}

After analyzing hazards, you (with the help of your team of workers, SMEs, and perhaps, the PIC) will choose controls. The purpose of controls is to reduce or eliminate the risk of the hazards. The following diagram illustrates the hierarchy of controls.
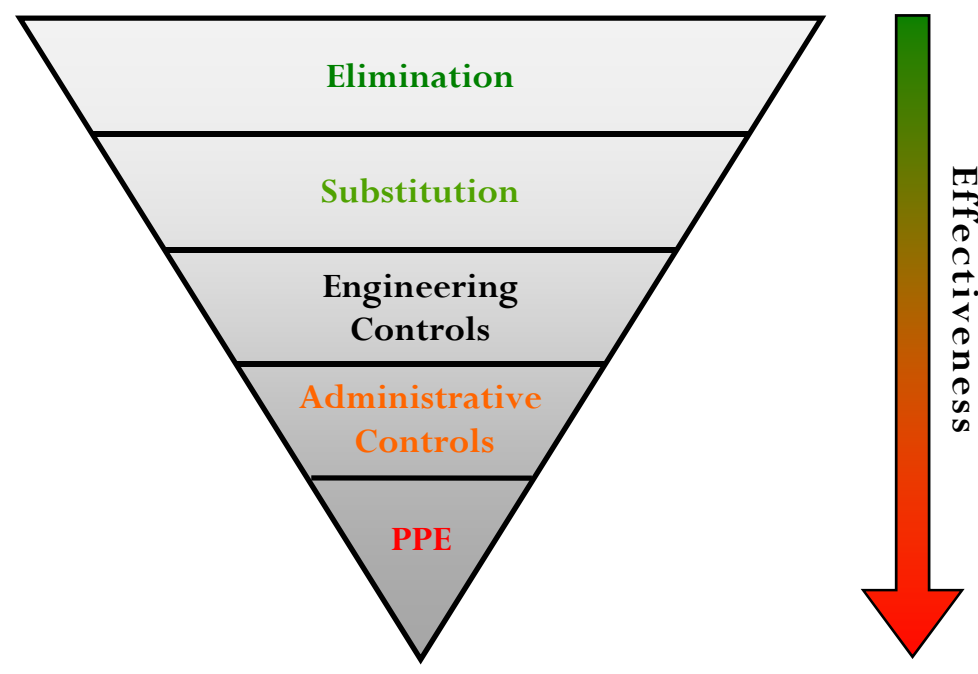

Hierarchy of controls, from most effective to least effective.

\section{Elimination}

Elimination removes the hazard from the operation and is the most preferred method of controls.

\section{Substitution}

Substitution is the replacement of a highly hazardous material or process with a less-hazardous or nonhazardous material or process. The hazards of the replacement component must be analyzed, and appropriate controls must be assigned.

\section{Engineering Controls}

Engineering controls are mechanical or structural systems used to reduce or minimize hazards. Examples of engineering controls include

- Ventilation systems

- Remote handling

- Glove boxes

- Fume hoods 
Two limitations of engineering controls are that they can fail and that people can deactivate or bypass them. These limitations are why the P300 hazard table states that the assigned hazard level can be reduced only if "engineered controls have been established, thoroughly reviewed, and proven highly reliable in minimizing the risks without active worker involvement."

\section{Administrative Controls}

Administrative controls are requirements that are established to minimize hazards. Examples of administrative controls include

- IWDs

- Procedures

- Approvals

- Signage

- Limits on exposure time

- Training

\section{Personal Protective Equipment (PPE)}

PPE is equipment and clothing worn to protect an individual from hazards when the hazard cannot be reduced or eliminated through a more preferable means of control. PPE is the least preferred method of control and should be used only to supplement other controls. PPE is often used as a second line of defense or as redundant control.

Examples of PPE include

- Protective clothing (lab coats, coveralls, gloves, hard hats, and safety shoes)

- Protective eye wear (safety glasses, goggles, and face shields)

- Hearing protection (noise-diminishing ear covers or plugs)

- Respiratory equipment

For more training on PPE, see LANL COURSE 28886, PPE Introduction Self-Study. 


\section{Specificity of Controls}

P300 requires that specific controls be chosen for each hazard and that these choices be documented in the IWD. Failure to follow this requirement forces workers to make choices about appropriate controls as they are doing the job. These workers could choose an inadequate control, or the appropriate control might not be available, which at best, delays the job. At worst, the worker might proceed with the work without adequately reducing the risk of the hazard; this could lead to worker injury or harm to the system, environment, or public.

Choose controls that fit the work. Do not impose unnecessary controls. Worker comfort is important; workers are unwilling to wear uncomfortable, ill-fitting PPE. Also, safety can be compromised by cumbersome PPE that is hot or that limits visibility, mobility, or respiration.

Workers are more likely to use controls that are readily available and easily used; they are also more likely to use controls when they understand how and why they are using them. As controls are chosen, analyze the corresponding hazard so that you are not inadvertently increasing risk or changing the hazard.

\section{Communicate Controls to Workers}

The IWD is a tool to communicate information about the controls to the worker. PICs and workers cannot use controls effectively if they are confused about

- The exact control that should be used

- How to use a control

- When to use a control

- Why to use a control

The preparer should consult PICs and workers before the work begins to ensure that they agree with the preparer's control choices.

Although not a P300 requirement, information about controls should also be incorporated into procedures. The link between the IWD and procedures should be clear. 
A standing IWD (SIWD) or a standard work control document (SWCD) may be used for repetitive, moderate-hazard and high-hazard/complex work in single or multiple facilities.

These documents are standardized, previously developed, and approved IWDs Part 1 combined with an appropriate Part 2 for each facility and list the specific facility entry and coordination requirements and work-area hazards. In each case, the preparer must ensure that the activityspecific and work-area requirements do not conflict.

\section{Job Hazard Analysis (JHA) Team Expectations}

A JHA team with the appropriate SME(s) is expected for highhazard/complex activities. The team must have an appropriate depth and breadth of expertise to identify and analyze the risks thoroughly and to determine how effective risk mitigation will be achieved. The preparer leads the team and must include the team workers who are assigned or representative workers who are knowledgeable and competent with respect to the activity. SMEs selected by the preparer and as stipulated by the RLM or FOD must be involved to ensure that the analysis is complete and effective. Unless specifically exempted by the FOD, the names of the team participants should be documented on Form 2100 or an equivalent WCD.

An HA team may also be used for moderate-hazard activities. However, a systematic HA must be performed, and the preparer must include workers representative of those involved in the activity.

\section{Documentation Requirements}

Low-hazard work performed by a worker who has been determined by the RLM to be competent for the defined scope of work does not require an IWD or an equivalent work document. For moderatehazard and high-hazard/complex activities, the work process, hazards, and controls must be documented in an IWD or WCD such as a technical procedure. IWDs and WCDs help workers understand when and how the controls are to be used. IWDs and equivalent WCDs must systematically describe the work activity, the associated hazards, and the controls necessary to mitigate the hazards.

The IWD must

- Focus on the information needed by the worker

- Be sufficiently detailed to ensure that the worker can understand the hazards and controls

- Have the tasks/steps listed sequentially when that sequencing contributes to safety

- Have hazards and associated controls linked to specific activity tasks/steps when that linkage is beneficial

- Address activity and work area hazards

- Have specific, not generic descriptions of hazards and associated controls 
- Have UTrain curricula, permits, and area postings referenced if they are required controls

Note: Qualified Worker Activities (defined in the LANL Definition of Terms), supported by qualification and training requirements, do not require a separate IWD.

The FOD is responsible for documenting and communicating workarea information, including the hazards associated with the facility or location in which the work is performed. The work area information will be documented in the IWD, Part 1; IWD, Part 2; or an equivalent WCD.

The FOD (or representative) and the RLM/Preparer must work together to ensure that the work can be performed safely, securely, and in an environmentally responsible manner within the facility or at the location designated for the work. If an IWD is not being used, an equivalent WCD would be managed in a similar way.

\section{LANL Policy Documents and Hazard Level}

The following documents are examples of LANL policy documents that discuss hazard assessment and grading:

- Integration of radiological work control with IWM is covered in P121, Radiation Protection, Chapter 11, "Radiological Work Control." Specifically, hazard grading of radiological hazards is addressed in P121.

- P101, Electrical Safety, contains some information regarding IWDs and reducing the hazard level by using approved engineering controls. See Chapter 4 for assessing electrical hazards.

For a complete and current listing of LANL policies, see http://policy.lanl.gov.

\section{Scoping Walk-Downs}

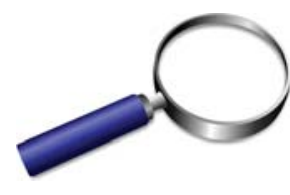

To perform an accurate and complete $\mathrm{HA}$, and ultimately to develop a meaningful IWD, work must be defined in sufficient detail to enable hazards to be identified, along with the circumstances under which they could cause harm (see P300, Section 3.1.1). In many cases, workers and SMEs may not have adequate knowledge of worksite conditions to define the work in sufficient detail to identify hazards and establish controls; this may require a "scoping walkdown." A scoping walk-down of the work site is an excellent way to learn more about 
- The facility or location where the work is to be performed

- The configuration and use of equipment

- Security concerns

- Co-located activities and hazards

- Potential environmental impacts

The need for a scoping walk-down should be determined jointly by the RLM accountable for the safety, security, and environmental compliance of the work activity and the relevant PIC. Participation by key workers, SMEs, or both also should be considered. The LANL Hazard Analysis Handbook (found in the IWM Toolbox and discussed in Module 2) provides more information on good practices for scoping walk-downs, including the use of a scoping checklist to ensure that key hazards are not overlooked.

The LANL Hazard Analysis Handbook is located on the IWM website:

LANL home page $>$ Safety $>$ Integrated Work Management $>$ Tool Box > Hazard Analysis Aids > Hazardous Analysis Handbook

http://int.lanl.gov/safety/integrated work management/toolbox/ ass ets/docs/hazard-analysis-handbook-Rev1.pdf

List the tasks in sequence. This phase allows participants to analyze situational hazards and helps to identify any steps that must occur in a particular sequence. Decide whether the necessity of sequence will affect performance, safety, security, or the environment.

When doing the walk-down, identify any outside factors that could influence the activity; this might be a facility setup or a co-located activity.

Consider any relevant worker factors, such as

- Special training

- Access requirements

- Co-located personnel

Ensure that information about the following items at the job site matches what is on paper:

- Materials

- Equipment 
- Security

- Environment

During the walk-down, the primary goal is to ensure that the activity on paper agrees with real life. The scoping walk-down participants might also begin to identify hazards as they notice them. Collect that information and incorporate it into the JHA.

Information in the following items also might be helpful to the JHA team:

- Accident and incident reports

- Health and safety committee minutes

- Previous inspection reports

- Previous JHAs

- Work procedures

- Manuals

- Maintenance records

- Lessons learned

- Material safety data sheets

\section{Coordination of Activities with Multiple Workers/Locations}

Coordination of activities involving multiple workers, workers from multiple line organizations, or workers at multiple locations poses additional challenges to the work control process. In some cases, the activity may be divided into multiple IWDs, thereby reducing the complexity of the individual IWDs. In such situations, it is important that interfaces between individual IWDs are well defined and do not introduce gaps in the work control process or create uncertainty in expected conditions or roles.

In cases where multiple line organizations must be involved within the scope of a single IWD (either because workers are from multiple organizations or because the activity will occur in shared space), P300 requires that responsibilities be defined clearly for each RLM before the work begins. For this purpose, one RLM and one PIC must have overall responsibility for ensuring that the work is defined adequately, the hazards are analyzed and mitigated, and the team and work site are ready (see P300, Section 3.1.1, Define the Work for a more detailed discussion). 


\section{Module 2: Preparing the IWD}

\section{IWD Purpose}

The IWD is a key document used in the IWM process to describe the work activity, identify the hazards, and link them to specific controls. The IWD is a tool that the preparer uses to

- Document the results of the activity definition and steps

- Document hazards, controls, and training

- Communicate the JHA results to the PIC and workers so that the information can be used during work

- Recall the JHA results at a later time

The IWD by itself will not keep workers safe. PIC and worker involvement in the IWM process will increase safety. The IWD helps communicate the results of the IWM process to the PIC and workers so that they can be aware of ways to increase safety.

\section{IWD Types}

Two types of IWDs may be written depending on the general work circumstances.

- Moderate-hazard and high-hazard/complex IWDs

- SIWDs)

Information about P300 requirements for the different types of IWDs follows. Some organizations do not allow the use of both IWD types. See your RLM and FOD for additional organizational requirements.

\section{Moderate-Hazard and High-Hazard/Complex IWDs}

Moderate-hazard and high-hazard/complex IWDs:

- Are used for moderate-hazard or high-hazard/complex activities

- Are used for unique activities in one facility or location

- Are used for activities performed once or multiple times

- Have an expiration date, which can range from day(s) to years 


\section{Standing IWDs (SIWDs)}

For repetitive, moderate-hazard and high-hazard/complex work activities in single or multiple facilities, an SIWD or SWCD may be used, provided that the RLM and Preparer have considered risk factors. Risk is defined as the qualitative (e.g., "high" or "low") expression of the possibility of an event occurring based on the probability that a hazard will cause harm and the consequences of that event. Risk considerations include the frequency and complexity of the work activity as well as the hazards of the work and the environment.

Hazards, as used here, include sources of danger (i.e., material, energy source, or operation) with the potential to cause illness, injury, or death to a person (workers or the public), or damage to a facility, or to the environment.

Changing work entry conditions have the potential to affect the risk of the activity. RLMs need to ensure that the initial work scope analysis, associated documentation, and related actions are commensurate with the complexity of the work, performance risk, and activity-specific and facility- specific conditions. If changing work entry conditions make the risk unacceptable, the work planner and RLM should reanalyze the hazards.

Although risk generally increases as complexity increases, complexity with or without risk factored in may still require an entirely different strategy in the graded approach to the development and field evaluations of SIWDs and SWCDs. For example, the work may become more complex with increases in the numbers of work hazards, workers, conflicting controls, or permits required.

SIWDs and SWCDs consist of a standardized, previously developed, and approved IWD, Part 1 (or equivalent), including the appropriate work area information (e.g., specific facility entry and coordination requirements and work-area hazards), or combined with an appropriate Part 2 (if used) for each facility listing the work area information. In each case, the person who prepares the IWD or equivalent WCD must ensure the activity-specific and work-area requirements are all included and do not conflict. In addition, at the time the work is scheduled to begin, the PIC must give consideration to whether work entry conditions must be specified in the SIWD or SWCD and include them if appropriate. 
Activities covered by SIWDs/SWCDs require the PIC to walk down the actual system or equipment and conduct a pre-job brief before beginning work. Only one pre-job brief is required if the work is performed repetitively in the same location with the same workers. A new pre-job brief is required when resuming work where conditions or process parameters have or may have changed. However, high risk/high complexity activities require a pre-job brief before each evolution.

\section{Qualified Worker Activities}

\section{IWD Parts}

The four parts to the IWD are

- Part 1, Activity Specific Information

- Part 2, FOD Requirements and Approval for Entry and Area Hazards and Controls

- Part 3, Validation and Release

- Part 4, Feedback/Post-Job Reviews

The preparer is responsible for completing Parts 1 and 2 of the IWD. The preparer also obtains RLM approval and FOD authorization for Part 1 and FOD approval for Part 2.

Note: Part 2 is optional, but if Part 2 is not used, the work area information, including hazards and controls, must be included in Part 1.

When performing the JHA for moderate-hazard and highhazard/complex activities, the preparer identifies

- Work tasks/steps

- Hazards, concerns, and potential accidents or incidents associated with the task steps

- Controls, preventive measures, and bounding conditions

- Reference documents

- Training requirements.

These HA results are documented in Parts 1 and 2 of the IWD, which is then used as a tool to communicate these results to workers. 


\section{Part 1 of the IWD (Activity Specific Information)}

Note: Part 1 of the IWD is also known as Form 2100. This form can be found in the Forms Center on the LANL website in the Toolbox on the IWM Website, along with the other IWD-related forms.

The IWD, Part 1, must meet the following requirements:

- The IWD must be worker friendly with a focus on information formatted as needed by the worker (such as being short, well organized, integrated, consolidated, and easily reviewed).

- Activities must be described in sufficiently detailed tasks/steps to ensure that the worker can understand the associated environment, safety, health, and quality/security and safeguards (ESH\&Q/S\&S) hazards, concerns, and potential accidents/ incidents.

- Tasks/steps must be listed sequentially when such sequencing contributes to the safety, security, and/or environmental protection of the activity.

- Hazards and the associated controls must be linked to specific activity tasks/steps when such linkage will contribute to the worker's understanding of the risks and use of the controls.

- Activity and work-area hazards and the associated controls must be addressed.

- Descriptions of hazards and associated controls must be specific and not generic.

- Training/authorizations, approved permits, and area postings must be referenced if they are required controls; if these controls are used, specific details do not have to be listed.

The amount of information added to an IWD beyond P300 requirements depends on the needs of the worker/owner of the IWD.

Note: Be cautious about assuming that the IWD is being written for an experienced worker because it is not always known if an experienced worker will be assigned to the work.

Some groups prefer to add procedural steps that are not associated with a hazard. P300 does not require that steps without hazards be included in the IWD; the preparer, workers, PIC, SME, and RLM must decide if the level of detail is appropriate. 
Training must be listed if it is a required control. List training and qualification requirements that are specific to performing the work activity at hand rather than all of the training required to be a LANL employee. For example, each LANL employee must attend General Employee Training (GET) and pass the GET test. However, GET would not be a training requirement listed for the performance of an identified work activity.

\section{Part 2 of the IWD (FOD Requirements and Approval for Entry and Area Hazards and Controls)}

Part 2 of the IWD, which is used to document work-area and facility information, identifies

- The FOD representative

- Entry and coordination requirements

- Facility or work-area information needed by the workers on the activity

The FOD is responsible for and required to document and communicate work-area information in the Facility Notes in the JHA Tool, including the hazards associated with the facility or location in which the work is performed. The preparer must ensure that the work activity requirements in Part 1 of the IWD are compatible and align with the work-area requirements documented in Part 2 of the IWD.

The FOD or his/her representative, and the RLM/preparer must work closely to ensure that the work can be performed safely, securely, and in an environmentally responsible manner within the facility or at the location designated for the work.

\section{Tenant and Non-Tenant, Part 2}

Different Part 2 forms are used for

- Non-tenants (Form 2101)

- Tenants (Form 2102)

The tenant and the non-tenant forms have identical sections for

- The FOD representative

- Entry and coordination requirements 


\section{Non-Tenant}

In the section concerning facility or work-area information needed by the workers, the non-tenant form is more detailed than the tenant form. For non-tenants, this information is documented in the following categories:

- Ionizing radiation

- Work area hazards/concerns

- Worker exposure

- Energized and operative systems

- Confined spaces

- Elevated work surfaces

- Environmental impact

- Security requirements

- Other hazards

For non-tenants, the hazard is specified in each category, along with the corresponding:

- Facility controls/preventive measures/bounding conditions

- Reference documents

- Training and qualifications

\section{Tenant, Part 2}

The tenant form does not list the hazards in the same way as the non-tenant form because it is assumed that tenants have a working knowledge of their facility as a result of facility training that non-tenants have not received, such as site-specific training.

\section{Considerations for Tenants and Non-tenants}

Regardless of the format of Part 2 of the IWD, both tenants and nontenants must be aware of the hazards and must implement effective controls for facility or co-located hazards. Managers should encourage workers to be more aware of the following issues:

- How work impacts the facility authorization or safety basis

- Facility emergency plans 
Managers should encourage workers, whether they are tenants or non-tenants, to be more aware of the following issues:

- How work impacts the facility safety or authorization basis

- Facility emergency plans

\section{Writing Parts 1 and 2 of the IWD}

You may create Parts 1 and 2 of the IWD by completing Forms 2100 and 2101/2102. Alternatively, you may create an equivalent WCD. The WCD must have the same content and approval/authorization/release signatures as the IWD, Parts 1 and 2.

For high-hazard/complex activities, the names of the -HA team participants should be documented (such as on Form 2100 or equivalent WCD).

\section{Validation Walk-Down}

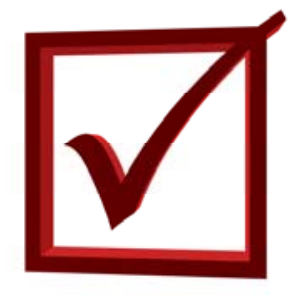

Before any work is released, a "validation walk-down" of the IWD (or equivalent WCD) must be performed to review tasks and steps for workability and to ensure that the hazards and controls are described effectively. The walk-down should be performed at the work site when possible and as close in time as feasible to the actual start of the work. This validation walk-down of the IWD must involve the PIC, workers (or qualified worker representatives of those who will participate in the work), and SMEs for highhazard/complex work or when determined appropriate by the RLM and/or PIC.

Documentation of the validation walk-down is required on Form 2103, IWD Part 3, Validation and Work Release. For highhazard/complex work, the validation walk-down must also involve appropriate SMEs, and subsequent walk-downs will be determined by the RLM or PIC based on the hazards and complexity of the activities. Any issues identified during the validation walk-down must be resolved before the work is started.

\section{IWD Parts 3 and 4}

The preparer is not responsible for completing Parts 3 and 4 of the IWD; however, preparers should review previously completed IWD Part 4 forms for information of value regarding lessons learned and feedback. Most of the responsibility for Parts 3 and 4 lies with the $\mathrm{PIC}$ and will be discussed further in the conclusion of this course. 


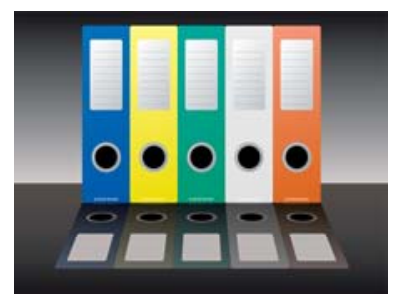

\section{Document Control Requirements}

WCDs must be kept current; they must be revised and reauthorized as appropriate, incorporating information from ongoing readiness checks and lessons learned. To ensure that only the most current and approved versions are used to guide work, P300 also requires effective document control for WCDs.

Effective document control must include an effective change control process that communicates changes to workers as soon as they are made and approved. The change control process must also ensure that workers have the currently approved work control documentation. For the purposes of change control and records management, the four parts of the IWD (or equivalent WCDs) may be treated as separate documents.

All LANL WCDs are expected to be reviewed every 3 years, unless determined otherwise by the RLM or FOD. WCDs for work activities in multiple FOD jurisdictions require those respective FOD or FOD representative approvals, as applicable.

If specific work activity procedures, such as detailed operating procedures, standard operating procedures, and work instructions that are considered equivalents or part of the IWD expire before the WCD expiration date, then the WCD is potentially no longer valid. If a revision of a referenced document does not impact an IWD/WCD, then the IWD/WCD remains valid. 


\section{Module 3: Hazard Analysis Methods}

\section{Overview}

$\mathrm{HA}$ is a critical component of planning and preparing for any LANL work activity. P300 requires using the hazard grading table to assess the hazard level posed by a specific activity. If the activity meets the criteria for moderate-hazard or highhazard/complex activities, an additional, more detailed HA is required as part of the IWD development process.

Documentation of the HA method used is located in IWD, Part 1.

To assist workers in becoming more proficient in the HA process, the Associate Director for Environment, Safety, Health, and Quality (ADESH\&Q) developed the LANL Hazard Analysis Handbook (ESH-HA-HANDBOOK-01) as a resource. This handbook provides detailed discussions that explain many HA methodologies and useful perspectives, along with examples of how these approaches can be used. The LANL Hazard Analysis Handbook is available from the Toolbox located on the IWM website.

The LANL Hazard Analysis Handbook is located on the IWM website:

LANL home page $>$ Safety $>$ Integrated Work Management $>$ Tool Box > Hazard Analysis Aids > Hazardous Analysis Handbook

http://int.lanl.gov/safety/integrated work management/toolbox/ a ssets/docs/hazard-analysis-handbook-Rev1.pdf

A short discussion covering each of the HA methods and perspectives presented in the LANL Hazard Analysis Handbook follows. 


\section{What-If/Checklist Technique}

The What-If/Checklist technique makes use of the normal human questioning process that comes quite naturally to most workers. This process asks questions about systems and activities to identify hazards and hazardous circumstances. These questions are generally in the form of "What if . . . ?" questions:

- What if the temperature drops?

- What if step 3 is skipped?

- What if an energized system is contacted during penetration at point $B$ ?

After a "what-if" list has been established through this questioning process, the following questions are asked for each item on the list:

- Could the consequences of the event be significant?

- Are existing controls adequate to

- Bring the risk of the event happening acceptably low?

- Mitigate the consequences to an acceptable level of risk?

- Should additional controls or process changes be considered to further mitigate the likelihood of undesired events or the consequences of those events?

The "what-if" part of this technique, which is the creative "brainstorming" aspect, is followed by a structured review using one or more checklists. Checklists integrate consistency and knowledge from prior experience into the what-if process. When used together, these methods offer a systematic approach for

- Identifying potential equipment failure, human errors, and offnormal conditions

- Determining the potential that such events have for creating hazardous circumstances

- Identifying controls that can eliminate or reduce the consequences of those circumstances

The What-If/Checklist technique frequently uses a team approach, which is required for high-hazard/complex activities. The team must comprise individuals who know and understand the specific activities of the proposed work and the basic hazards associated with each activity. The team also needs a leader who can keep the brainstorming process moving and the team focused. 
The team leader is responsible for

- Providing structure to the questioning process by breaking the activity down into manageable units

- Stimulating new lines of inquiry by asking questions when the discussion lags

- Ensuring that appropriate checklists are available after the completion of the brainstorming exercise

It is frequently useful to combine the "What If?" analysis with perspectives provided by other HA methods, such as failure modes and effects analysis (FMEA) or HAZOP, as discussed in the following paragraphs.

\section{HAZOP Analysis}

The HAZOP analysis is a structured brainstorming method for conducting HA by a team of knowledgeable personnel. HAZOP systematically investigates each element of a system or process for the ways that important parameters can deviate from the intended design conditions to create hazards and operability problems.

HAZOP studies are based on the assumption that systems operating under design conditions work well and that problems arise when deviations from design conditions occur. Possible deviations are many and diverse but may include

- Temperatures, pressures, or flow rates that are either higher or lower than the design intent

- Procedural steps that are either conducted in the wrong order or omitted entirely

- Reaction constituents that are incorrect, missing, or in addition to the planned reaction constituents.

The HAZOP team starts by defining the parameters of normal operation, the plausible deviations from the design parameters, and the effect(s) that each of these deviations might have on the system. HAZOP formality and rigor are ensured through the systematic use of guide words (such as more, less, and reverse) and standard system parameters (such as pressure, temperature, and concentration) that stimulate the team to think of ways that a procedure or process can fail. HAZOP guide words and system parameters can also serve as a checklist to supplement the what-if approach discussed previously. 


\section{Failure Modes and Effects Analysis (FMEA)}

FMEA is a methodical study of component failures that is useful for identifying potential component/system failure modes, the possible causes leading to component failures, and the likely consequences of such failures. FMEA starts with a process diagram that includes all of the components that could fail and possibly affect safety, such as instrument transmitters, controllers, and pumps. The potential consequences of component/system failures and their effects on the overall process are examined exhaustively. The FMEA method can also be helpful in identifying administrative control failure modes when processes are considered as a collection of administrative components/systems (such as evaluating the controls involved in radiological control scenarios).

A systems approach may also provide a useful perspective for supplementing a What-If/Checklist analysis. A list of system components and their failure modes can serve as a checklist and thereby provide a system focus that is significantly different from other perspectives, such as procedural steps, operator actions, or materials.

\section{Task Analysis}

Task analysis is fundamental to any HA approach that is used to divide the work into conceptually more manageable segments. Segments may be based on function, procedural applicability, location, worker roles, or common hazards. Standard HA methodologies (such as what-if/checklist, HAZOP, and FMEA) are then used to analyze each segment, paying particular attention to interrelationships between segments. Under task analysis, a segment might include a group of related procedural steps; however, unlike procedure analysis, task analysis does not normally consider each individual step as a segment. 


\section{Procedure Analysis}

Procedure analysis examines the activity as a series of consecutive steps that are analyzed individually and in the order that they are to be performed. Additional structure can be added through the use of HAZOP guide words for the procedure system parameter. The procedural perspective is particularly useful in identifying

- Missing or out-of-order steps

- Hold points

- Hazards and controls for specific steps

- Emergency actions

When multiple organizations are involved during a work activity, it is important to identify each RLM's responsibilities. Procedure analysis is an excellent way to coordinate work steps so that responsibilities are clearly identified. Procedural steps also can be viewed as a checklist to supplement a what-if analysis, either with or without the additional formality provided by HAZOP guide words.

\section{Scoping Checklist}

The most common and recognizable form of HA is the scoping checklist. A scoping checklist is a collection of predetermined hazards designed to remind the user of the many different possible hazards based on past experiences.

The scoping checklist is usually a printed list that the user can take to the field and use while inspecting the job site. In some cases, a pre-developed list is used to identify or communicate area hazards. A scoping checklist can be used as a tool to further develop the work document or as a formal approval of the hazards and controls identified.

The scoping checklist is usually used in conjunction with a job scoping walk-down. The scoping team selects and uses a previously developed checklist based on the intended scope of work. The team leader, planner, or preparer reviews the scope of work with the workers and SMEs, reviews listed hazards and controls, and typically checks off the items on the list that apply. This tool typically is used with a group to identify the hazards. The team leader/planner/preparer then uses the checklist as a guide for developing the instructions or work document. 
A scoping checklist is used as a guide during information gathering on a procedure or process at the worksite. This checklist can be developed from a list of standard hazards and controls or from the results of an activity HA. The checklist is then used during scoping walk-downs of the proposed work area to verify that hazards and controls have been identified adequately and are appropriate.

The inclusion of workers and SMEs as part of the scoping walkdown process makes use of their knowledge and experience to identify hazards and to assess the appropriateness and adequacy of controls. Scoping checklists are particularly useful when the RLM and PIC jointly determine that a scoping walkdown is necessary to ensure that work has been sufficiently defined to identify hazards and to ensure that controls are adequate to mitigate these hazards to an acceptable level.

\section{Barrier Analysis}

Barriers are controls designed to prevent accidents or to mitigate the consequences of accidents in the event that they do occur. Barrier analysis is used to evaluate employed or proposed controls to determine the adequacy of those controls. Controls may be

- Engineered (a component, piece of equipment, or structure used to separate the worker from the hazard)

- Administrative (permits, training, procedures, etc.)

PPE (work gloves, safety glasses, etc.), which should be used as a "last line of defense" and not in place of engineered or administrative controls

Barrier analysis is frequently used in post-incident investigations but can also be used in a proactive manner to evaluate controls identified by other HA methodologies, including the WhatIf/Checklist methodology. 


\section{Fault-Tree (Human Reliability) Analysis}

Fault-tree analysis assesses undesirable outcomes that could result from a specific initiating event. This analysis begins with a graphic that represents sequences of all possible events that could lead to an accident. The resulting diagram looks like a tree. Each branch of the tree lists the events (failure modes) for an independent path to the undesirable outcome at the top. Faulttree analysis is a complex method that is best led by a professional. This method is normally used during accident investigations but might also be used proactively, either formally or informally, as a way to assess the possible causes of undesirable outcomes from system failures and accidents.

\section{Human Performance Improvement's (HPI's) Role in Hazard Analysis}

Human error is viewed as the primary cause of most accidents. Human performance improvement (HPI) takes the perspective that workers do not cause accidents but instead trigger a set of underlying organizational weaknesses and latent conditions that result in accidents. Time pressure, poor communication habits, and unclear (or lack of) standards are just a few of the factors that create error-likely situations.

Regardless of which HA approach you use, HPI can play a part in identifying how the worker affects the work process. The HPI Task Preview diagrams and Error Precursor cards, in particular, can serve as useful checklists in conjunction with the What-If/ Checklist process. These diagrams and cards can be found in P300 Attachment $\mathrm{C}$. These work aids, along with additional HPI guidance documents, are also available online from the Toolbox located on the IWM website. Click on the "Tools" tab and then the "Hazards Analysis" tab. The link to the Toolbox is http://int.lanl.gov/safety/integrated work management/toolbox/ind ex.shtml.

The HPI website (http://int.lanl.gov/org/padops/adesh/integrationoffice/human-performance-improvement/index.shtml) provides additional tools, information, and training. 


\section{Additional IWM Information}

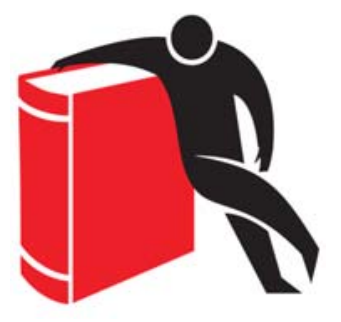

The IWM website and Toolbox are resources for links to relevant requirements, job aids, and examples supporting IWM implementation. In addition, the Toolbox provides

- IWD examples (see the "IWDs" tab under "Tools")

- links to guides for procedure writers (see the "Guides" tab under "Tools")

- templates for IWM forms (see the "Forms" tab under "Tools")

- contact information for key IWM program personnel, FODs, and ESH\&Q managers.

The Toolbox is located at the following link:

http://int.lanl.gov/safety/integrated work management/toolbox/ind ex.shtml

Additional materials and suggestions that would benefit IWM implementation are always welcome. Contact the IWM SME through the IWM website at http://int.lanl.gov/safety/integrated work management/index.shtml. 